\title{
Orofacial Characteristics in Relation to the Need of Orthodontic Treatments in Children
}

\author{
Caracteristicas Orofaciales en Relación a la Necesidad \\ de Tratamiento Ortodóncico en Niños
}

Paulo Sandoval Vidal*; Mónica Ceballos Casanova*; Claudia Acevedo Atala* \& Alejandra Jans Muñoz ${ }^{* *}$

SANDOVAL, V. P.; CEBALLOS, C. M.; ACEVEDO, A. C. \& JANS, M. A. Orofacial characteristics in relation to the need of orthodontic treatments in children. Int. J. Odontostomat., 4(1):59-64, 2010.

Abstract: Malocclusion represents a public health problem in Chile. Government policies create preventive and interceptive programs for these conditions. Nevertheless, there are no uniform criteria for the selection of patients who need early treatment; the decision is made by a specialist during orthodontic treatment. Here, we propose the Index for Early Intervention (IEI) for early detection of malocclusions. We treat malocclusions with a simple interceptive treatment to minimize or eliminate the need for orthodontic treatment in a child population. Furthermore, the IEI can be used in general dentistry as a screening method. The purpose of this study was to compare the reliability and validity of an index used to assess the need for orthodontic treatment, as compared to the view of a panel of experts formed by three orthodontists. We used a set of 55 study casts representing all types of malocclusion. The accuracy of the diagnostic or the validity of each index was calculated using the opinions of three orthodontic raters as a "gold standard;" these measures obtained an agreement of 0.82 . Receiver Operating Characteristic curves was plotted for the index. Results: Diagnostic accuracy was determined by the area under the curve, the cut point was 20 , sensitivity was 0.977 and specificity was 0.167 . Conclusions: This occlusal index provided valuable information for selecting children in need of early and simple orthodontic treatment.

KEY WORDS: malocclusion, occlusal index, screening.

\section{INTRODUCTION}

Preventive and interceptive orthodontics can potentially eliminate the need for treatment and reduce the cost of future extensive orthodontic treatment. Patient education, fluoride, sealants, regular screenings and basic restorative work can further enhance the preventive orthodontic approach. Furthermore, important interceptive orthodontic work can be accomplished with relatively inexpensive removable appliances, such as expansion appliances, habitbreaking appliances, space maintainers and crossbite correction appliances.

The orthodontic field has developed indexes that facilitate a diagnosis and provide an opportunity for derivation, including the Index of Orthodontic Treatment need (INTO) (Brook \& Shaw, 1989), Dental Aesthetic
Index (DAI) (Cons et al., 1986), Handicapping Labiolingual Deviation (HLD-CaldMod) (Draker, 1960), Peer Assessment Rating index (PAR) (Richmond et al., 1992), Eismann Index (Eismann, 1974), Malocclusion Severity Index (MSI) (Hill, 1992) and the Index of Complexity, Outcome and Need (ICON) (Daniels \& Richmond, 2000).

Only a few studies dealt with preventive and interceptive orthodontics; one Canadian study applied a specific index for mixed dentition called the "Index for Preventive and Interceptive Orthodontic Need (IPION)" (Karaiskos et al., 2005). Although the IPION is a very useful tool, it lacks the sensitivity necessary for deciding which cases to accept for preventive or interceptive orthodontic treatment. Two studies were

\footnotetext{
* Orthodontic Chief, Assistent Professor, Departament of Dentistry Universidad de La Frontera, Temuco, Chile.

${ }^{* *}$ Assistent Professor, Departament of Dentistry Universidad de La Frontera, Temuco, Chile.

Supported by the DIDUFRO Nº 120438 Universidad de La Frontera, Chile.
} 
conducted in the United States (Ackerman \& Proffit, 1980; Popovich \& Thompson, 1973), two were performed in Finland (Heikinheimo \& Salmi, 1987; Jarvinen, 1981) and two in South Africa (Coetzee \& Wiltshire, 2000). Despite this low number of reports, many clinicians considered early intervention as a viable option in many malocclusion cases in early and later mixed dentition. In Chile, the demand for orthodontic treatment is increasing; nevertheless, the resources required are insufficient. We need a malocclusion index that will identify those with severe anomalies; that is, an index with high sensitivity and specificity. The validity of an orthodontic treatment is initially established by the opinions and experiences of a group of orthodontists; this is the first step in the acceptance of an index within the clinical community. Thus, an index can facilitate the study of malocclusion prevalence and addresses the need for orthodontic treatment in children and adolescents. This study validated an index to evaluate the need for interceptive orthodontic treatment in this part of Chile.

\section{MATERIAL AND METHOD}

We used 55 study casts of adolescents with mixed dentition, without orthodontic treatment (mean age 10 years SD 1.4 years; 24 girls and 21 boys) at the Dental Clinic of the Universidad de La Frontera of Temuco, Chile. The study casts were selected at random from a group of 98 preselected models that included all malocclusion types and severities. A panel of 11 orthodontists (graduates from three universities in Chile) individually rated each model by scoring it according to the need for treatment. Each orthodontist, using a 7-point Likert-type scale, scored each of 55 dental casts in response to the following question: "You are the orthodontic consultant for a private corporation for which a fund has been established to provide orthodontic treatment for personnel. You are to assess these 55 models of personnel and answer the following question: "In your opinion, to what extent does this occlusion need orthodontic interceptive treatment or, if it is very severe, corrective treatment". The scale for each model was bound by "minimal need" and "great need" (Table I).

To determine the validity of the created instrument, we used the consensus opinion of 11 Chilean orthodontists as the gold standard, using the Intraclass Correlation Coefficient (ICC). Intraexaminer and interexaminer agreement were evaluated to assess the reliability using the Intraclass Correlation Coefficient (ICC). The Receiver Operating Characteristic (ROC) curve was used to evaluate the overall accuracy of diagnosis (Fig. 1). A second assessment was performed 30 days later on some study casts in order to determine the reliability of a subgroup of 20 study casts. The severity of the malocclusion and the need for treatment are based on 13 morphological intra- and interarch measurements. The stratifying variable was malocclusion severity, as measured by the dental health component of IEI. To assess malocclusions, a special ruler was designed (Fig. 2) and all morphological finds were recorded for two examiners, trained and calibrated in the use of IEI. The training was done earlier in a set of 15 different models, with trainees guided by the examining orthodontist. The examiner repeated twice the scoring of 55 study casts in order to evaluate reliability between and among groups. Reliability was measured using the Intraclass Correlation (ICC).

With respect to the dental component of the index, we observed marked reliability of the diagnostic judgment among 11 orthodontists (sampling 55 randomly-selected models). The analyses were carried out with the coefficient of inter-class correlation for continuous variables. We found low percentages of correlation $(0.58, p=0.0001)$ between the experts. We subsequently retrained the orthodontists to improve agreement among them. One month later they were

Table I. Ranking system of index for interceptive orthodontic needs (IEI).

\begin{tabular}{lll}
\hline IEI & Description & Treatment need \\
\hline Grade 1 & No malocclusion & No need \\
Grade 2 & Small lack of incisive alignment & No need \\
Grade 3 & Minimal malocclusion & Interceptive \\
Grade 4 & Mild malocclusion & Interceptive \\
Grade 5 & Moderate malocclusion & Interceptive limit \\
Grade 6 & Severe malocclusion & Corrective \\
Grade 7 & Very severe malocclusion & Corrective \\
\hline
\end{tabular}


evaluated again; the three orthodontists with greatest inter- and intra-group agreement were selected. We thus validated the dental component of the index: the inter-examiner score was 0.851 (Table II).

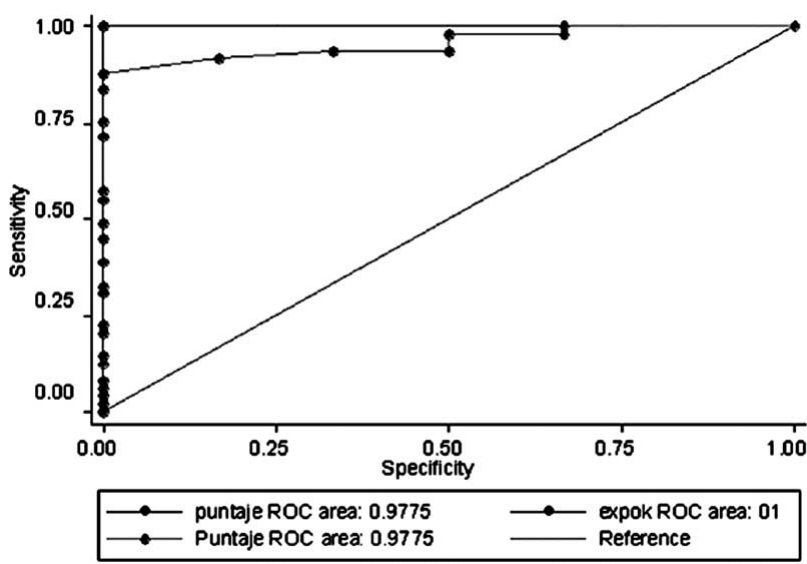

Fig. 1. ROC curve of for index for early interventions (IEI).
Table II. Index of intra- and inter-examiner variability (ICC) among 11 orthodontists in the first session and three orthodontists in the second session of Chile, Region IX. ICC Values above $0.61-0.80$ indicate substantial agreement; ICC Values above $0.81-1.00$ indicate perfect agreement.

\begin{tabular}{lcc}
\hline & \multicolumn{2}{c}{ Dental Health Component } \\
\cline { 2 - 3 } & First round & Second round \\
\hline Inter-examiner & 0.58 & 0.851 \\
\hline
\end{tabular}

Use of IEI. To validate the clinical arm of the IEI instrument, it was applied to the same 55 models studied. The results were the following:

To establish a numerical range associated with the need for treatment, the maximum of need estimated in these models was 30 points; the need for an interceptive orthodontic treatment ranged between 4 and 20 points. We established a cut-off point for the need of corrective treatment (sensitivity $=0.977$ and specificity $=0.167$ ) (Table III). These parameters imply that $98 \%$ of the patients who have a score of 20 will require interceptive treatment; there was a $17 \%$ chance that these would need corrective treatment (Fig. 3).

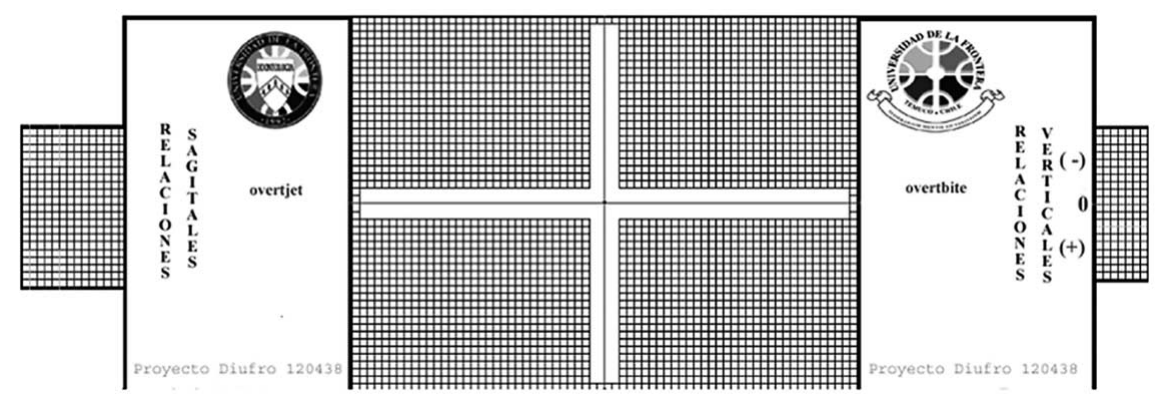

Fig. 2. Ruler for assessing malocclusion specially designed.

\section{Percentage of Cases}

\section{Corrective}

Interceptive Limit

Interceptive full

Not need of treatment

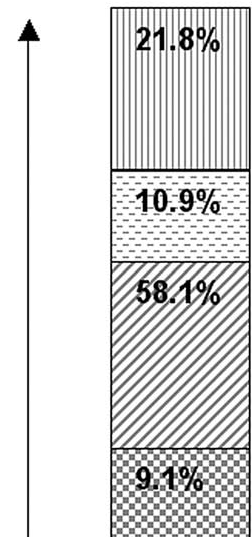

Gold Standard

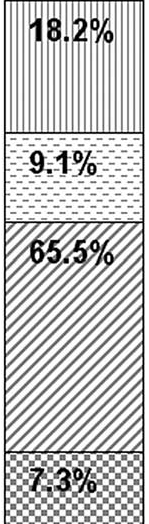

IEIGD
Fig. 3. Distribution for need treatment according the Gold Standard and index for early interventions IEI. 
SANDOVAL, V. P.; CEBALlOS, C. M.; ACEVEDo, A. C. \& JANS, M. A. Orofacial characteristics in relation to the need of orthodontic treatments in children. Int. J. Odontostomat., 4(1):59-64, 2010.

\begin{tabular}{|c|c|c|c|c|c|}
\hline \multirow[t]{2}{*}{ Test Variable } & \multirow[t]{2}{*}{ Area } & \multirow{2}{*}{$\begin{array}{l}\text { Standard } \\
\text { error }\end{array}$} & \multirow{2}{*}{$\begin{array}{l}\text { Asymptotic } \\
\text { signification }\end{array}$} & \multicolumn{2}{|c|}{ 95\% Confidence Interval } \\
\hline & & & & Lower bound & Upper bound \\
\hline IEI & 0.977 & 0.042 & $<0.0001$ & 0.845 & 1.008 \\
\hline
\end{tabular}

These results were compared with the opinion of the experts, who established the need for treatment in the same models. Agreement of $82 \%$ exists between the application of the instrument (IEI) and the expert consensus (Table IV).

\section{DISCUSSION}

This index demonstrated high reliability in classifying a wide range of malocclusions. Furthermore, the index correctly identified orthodontic treatment in $82 \%$ of malocclusion cases, as determined by agreement with the consensus opinion of a panel of orthodontists. This high diagnostic value is attainable when the provided index presents an appropriate cutoff point. This can happen when the need for treatment need is measured in an arbitrary way, possibly facilitated by the homogeneity of opinion in Chile. This can occur during post-graduate orthodontic training in Chile; the curriculum in this country is not accredited (despite criteria developed by the American Association of Orthodontists (AAO)). Nevertheless faculty members do not have a common understanding of what constitutes an interceptive treatment. For this reason, a second training session was required to forge agreement on the criteria for preventive orthodontics. We selected three orthodontists that exhibited the greatest agreement under the Intraclass Correlation Coefficient (ICC).

Preventive orthodontics promote the development of a normal occlusion and help to prevent malocclusion from developing. Interceptive orthodontics is a procedure to restore a normal occlusion once a malocclusion has started to develop. Intercepting a developing malocclusion with the resources provided by a public health program requires a simple method to identify or measure the degree of the malocclusion. Recently, the Index for Preventive and Interceptive Orthodontic Need (IPION) was described; it is the only documented index (Karaiskos et al.). IPION has a score of 5 grades, determined to be reasonable indicators of the need for preventive and interceptive orthodontic treatment. Among six-year-old children, $17(4 \%)$ had a score of 0 , as did 7 (3\%) of the nine-year-old group.
Table IV. Agreement between the index for interceptive orthodontic needs (IEIGD) and the gold standard. ICC= Intra-class coefficient correlation.

\begin{tabular}{ccc}
\hline Index & $\mathbf{P}$ & ICC \\
\hline IEI & $<0.0001$ & 0.0819 \\
& & $(0.0617-0.0826)$ \\
\hline
\end{tabular}

Most children had scores between 1 and 4; the proportion was higher among the six-year-olds $(61.7 \%)$ than among the nine-year-olds (55.7\%). A considerable group of children had a score of 5 or higher, as did 42 children in the six-year-old group (20.9\%) and 72 in the nine-year-old group (37.1\%). Two analyses revealed no statistically significant differences for sex and age. In research by others, nearly perfect interexaminer (Kappa 0.95) and intraexaminer (0.91) agreement was found; this is similar to the results obtained in our research. Interceptive treatment benefited $27(3 \%)$ of all treated cases. Fifteen percent of potential patients were evaluated to be good candidates for preventive and interceptive orthodontic treatment. However, we concluded that in spite of the potential benefit to these patients, it may not be practical to advocate a relatively expensive treatment modality on a population-wide basis (Jarvinen). Although the IPION is a very useful tool, it lacks the sensitivity necessary to decide which cases to accept for preventive or interceptive orthodontic treatment. No defined value has yet been established as a reasonable marker for corrective treatment (Karaiskos et al.): our index developed a cut-off point to distinguish between interceptive and corrective treatment (20 points), with better sensitivity than the IPION $(0.167)$.

The Index of Complexity, Outcome and Need (ICON) was developed as a single index for assessing treatment and its results. Researchers used a panel of 97 international orthodontists from IEGD (Daniels \& Richmond); participants provided subjective judgments on the need for treatment, complexity, improvement and acceptability of treatment for a diverse sample of 240 "initial" study models and 98 "treated" study models. Our study used only 55 models of pediatric patients whose initial consultation did not reveal malocclusion. 
In our study the experts were national and comprised of 11 orthodontists. The IEI presented a specificity of $16.7 \%$ and overall accuracy $97.7 \%$; these values indicate accuracy in predicting the need for treatment. The ICON could explain the $75.6 \%$ frequency of complexity in average cases and the $63.5 \%$ rate of improvement. This index is in accord with international parameters to determine the need, complexity and results of treatment. Because it was developed for definitive dentition, applying this index to mixed dentition may decrease validity of the results.

Some of the articles that evaluate the need for treatment in stages of mixed dentition used the Index of Need of Treatment of Orthodontics (IONT) created for Brook \& Shaw. Nevertheless this index is oriented toward the need for corrective treatment. In contrast, the IEI was conceived for the purpose of early treatment. In combination with effective interception of malocclusion, this index represents a powerful tool in developing countries where the access to an orthodontist is limited to those with greater economic resources. This reality makes it necessary to distinguish patients according to the severity of the anomaly and initiate early treatment.

In Finland, Keski-Nisula et al. (2003) used a classic anatomical description of anomalies as the basis of occlusal results. They studied subjects that took part in a clinical trial investigating the effects of orthodontic intervention in early mixed dentition. However, the results cannot be compared to our own because no index of malocclusion was used to characterize these findings; the same applies to the reports of Utomi (2005) and Onyeaso (2004) in Nigeria, and Schopf (2003), Stahl \& Grabowski (2003) in Germany.

Limitations of the present study. The results of this investigation are limited to the subjects involved, that is, children residing in the south of Chile. It could be suggested that these values might differ between geographical areas. However, this study provides the basis for further work in other parts of Chile and around the world.

\section{CONCLUSION}

We have created a rule of clinical prediction, through which it is possible to determine the need for interceptive orthodontic treatment with high validity and reliability. This instrument of investigation classifies the need for orthodontic treatment before the malocclusion is already established in definitive dentition. Therefore the Index for Early Intervention (IEI), applied to the dental component, allows orthodontists and general dentistry to select individuals that require early treatment of malocclusions.

SANDOVAL, V. P.; CEBALLOS, C. M.; ACEVEDO, A. C. \& JANS, M. A. Caracteristicas orofaciales en relación a la necesidad de tratamiento ortodóncico en niños. Int. J. Odontostomat., 4(1):59-64, 2010.

RESUMEN: La maloclusión representa un problema de salud pública en Chile. Políticas del Gobierno han creado programas preventivos e interceptivos para estas condiciones. Sin embargo, no existen criterios uniformes para la selección de los pacientes que necesitan tratamiento temprano, la decisión es tomada por un especialista durante el tratamiento ortodóncico. Aquí, proponemos el índice de Intervención Temprana (IIT) para la detección temprana de maloclusiones. Tratamos maloclusiones con un simple tratamiento de intercepción para minimizar o eliminar la necesidad de un tratamiento de ortodoncia en una población infantil. Además, el IIT puede ser utilizado en odontología general como un método de tamizaje. El objetivo de este estudio fue comparar la confiabilidad y validez de un índice utilizado para evaluar la necesidad de un tratamiento de ortodoncia, en comparación con la opinión de un panel de expertos formado por tres ortodoncistas. Se utilizó un conjunto de 55 modelos de estudio que representan todos los tipos de maloclusión. La precisión del diagnóstico o la validez de cada índice se ha calculado utilizando las opiniones de tres calificadores de ortodoncia como un "gold standard", estas medidas obtuvieron un acuerdo de 0,82. Las curvas de las características operativas del receptor fueron trazadas para el índice. La precisión diagnóstica fue determinada por el área bajo la curva, el punto de corte fue de 20, la sensibilidad fue del 0,977 y la especificidad fue del 0,167. Este índice oclusal proporcionó información valiosa para la selección de los niños que necesitan un tratamiento de ortodoncia temprano y simple.

PALABRAS CLAVE: maloclusión, índice oclusal, tamizaje.

\section{REFERENCES}

Ackerman, J. L. \& Proffit, W. R. Preventive and interceptive orthodontics: a strongtheory proves weak in practice. Angle Orthod., 50(2):75-87, 1980.
Brook, P. H. \& Shaw, D. C. The development of an index of orthodontic treatment priority. Eur. J. Orthod., 11(3):309-20, 1989. 
Coetzee, C. E. \& Wiltshire, W. A. Occlusal and oral health status of a group of 3-8- year-old South African black children. SADJ, 55(5):252-8, 2000.

Cons, N. C.; Jenny, J. \& Kohout, F. J. DAl: The Dental Aesthetic Index (DAI). lowa, College Dentistry University of lowa, 1986.

Daniels, C. P. \& Richmond, S. The development of the index of complexity, outcome and need (ICON). J. Orthod., 27(2):149-62, 2000.

Draker, H. L. Handicapping Labio-lingual Deviation Index: A proposed index for public Health purposes. Am. J. Orthod., 46:295-305, 1960.

Eismann, D. A method of evaluating the efficiency of orthodontic treatment. Trans. Eur. Orthod. Soc., 223-32, 1974.

Heikinheimo, K. \& Salmi, K. Need for orthodontic intervention in five-year-old Finnish children. Proc. Finn. Dent. Soc., 83(4):165-9, 1987.

Hill, P. A. The prevalence and severity of malocclusion and the need for orthodontic treatment in 9-, 12-, and 15-year-old Glasgow schoolchildren. Br. J. Orthod., 19(2):87-96, 1992.

Jarvinen, S. Need for preventive and interceptive intervention for malocclusion in 3-5-year-old Finnish children. Community Dent. Oral Epidemiol., 9(1):1-4, 1981.

Karaiskos, N.; Wiltshire, W. A.; Odlum, O.; Brothwell, D. \& Hassard, T. H. Preventive and interceptive orthodontic treatment needs of an inner-city group of 6- and 9-year-old Canadian children. J. Can. Dent. Assoc., 71(9):649, 2005.

Keski-Nisula, K.; Lehto, R.; Lusa, V.; Keski-Nisula, L. \& Varrela, J. Occurrence of malocclusion and need of orthodontic treatment in early mixed dentition. Am. J. Orthod. Dentofacial Orthop., 124(6):631-8, 2003.

Onyeaso, C. O. Need for preventive/interceptive orthodontic treatment among 7-10-year-old children in Ibadan, Nigeria: an epidemiological survey. Odontostomatol. Trop., 27(107):15-9, 2004.

Popovich, F. \& Thompson, G. W. Evaluation of preventive and interceptive orthodontic treatment between 3 and 18 years of age. Third International Orthodontic Congress, 1973. pp.260-81.

Richmond, S.; Shaw, D. C. \& Roberts, C. T. The PAR index (Peer Assessment Rating) method to determine outcome of orthodontic treatment in terms of improvement and standards. Eur. J. Orthod., 14:180-7, 1992.

Schopf, P. Indication for and frequency of early orthodontic therapy or interceptive measures. J. Orofac. Orthop., 64(3):186-200, 2003.

Stahl, F. \& Grabowski, R. Orthodontic findings in the deciduous and early mixed dentition--inferences for a preventive strategy. J. Orofac. Orthop., 64(6):40116, 2003.

Utomi, I. L. Need for interceptive intervention for malocclusion in handicapped children in Lagos, Nigeria. Afr. J. Med. Med. Sci., 34(3):239-43, 2005.

Correspondence to:

Paulo Sandoval Vidal

Department of Orthodontics

Medicine Faculty

Universidad de La Frontera

Manuel Montt 112

Temuco

CHILE

Fono: 56-45-214841

Fax 56-45-325777

Email: hpsandov@ufro.cl

Received: 30-04-2009

Accepted: 22-12-2009 